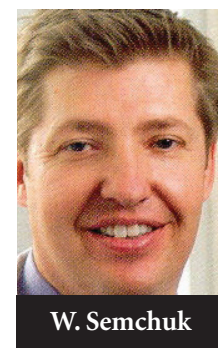

Venous thromboembolism (VTE) is an important complication of and a common cause of death in patients with cancer. Evidence exists providing direction to clinicians in both prophylaxis and treatment of VTE in cancer patients. Despite this guidance, treatment gaps exist. Pharmacists have the opportunity to minimize the care gap. La thromboembolie veineuse est une complication importante et une cause fréquente de décès chez les patients atteints de cancer. Bien que les données actuelles fournissent une orientation aux cliniciens pour la prophylaxie et le traitement de la thromboembolie veineuse chez ces patients, des lacunes persistent. Or, les pharmaciens ont la possibilité de réduire au minimum ces lacunes en matière de soins.

\title{
Prevention and treatment of venous thromboembolism in patients with cancer
}

\author{
William M. Semchuk, MSc, PharmD, FCSHP; Catherine Sperlich, MD, FRCPC, BSc
}

\section{Abstract}

Background: Many patients who experience a venous thromboembolic event have cancer, and thrombosis is much more prevalent in patients with cancer than in those without it. Thrombosis is the second most common cause of death in cancer patients and cancer is associated with a high rate of recurrence of venous thromboembolism (VTE), bleeding, requirement for long-term anticoagulation and poorer quality of life.

Methods: A literature review was conducted to identify guidelines and evidence pertaining to anticoagulation prophylaxis and treatment for patients with cancer, with the goal of identifying opportunities for pharmacists to advocate for and become more involved in the care of this population.

Results: Many clinical trials and several guidelines providing guidance to clinicians in the treatment and prevention of VTE in patients with cancer were identified. Current clinical evidence and guidelines suggest that cancer patients receiving care in hospital with no contraindications should receive VTE prophylaxis with unfractionated heparin (UFH), a low-molecular-weight heparin (LMWH) or fondaparinux. Patients who require surgery for

\section{Introduction}

Venous thromboembolism (VTE), including deep vein thrombosis (DVT) and pulmonary embolism, is a common complication of cancer and its treatment and occurs more frequently in patients with cancer than in patients without it. Patients with cancer have an annualized risk of VTE 6 to 12 times higher than those without cancer. ${ }^{1}$ Among patients with cancer, VTE is strongly associated their cancer should receive prophylaxis with UFH, LMWH or fondaparinux. Cancer patients who have experienced a VTE event should receive prolonged anticoagulant therapy with LMWH (at least 3 months to 6 months). No routine prophylaxis is required for the majority of ambulatory patients with cancer who have not experienced a VTE event. Most publicly funded drug plans in Canada have developed criteria for funding of LMWH therapy for patients with cancer.

Conclusions: Evidence suggests that LMWH for 3 to 6 months is the preferred strategy for most cancer patients who have experienced a thromboembolic event and for hospital inpatients, but this is often not implemented in practice. Concerns about adherence with injectable therapy should not prevent use of these agents. Pharmacists should assess cancer patients for their risk of VTE and should advocate for optimal VTE pharmacotherapy as appropriate. If LMWH is the preferred agent, on the basis of the evidence, the pharmacist should educate the patients appropriately and work with the prescriber to ensure best care. Can Pharm J 2012;145:24-29.

with reduced survival, ${ }^{2}$ and thromboembolism is the second leading cause of death among outpatients who are receiving cancer therapy. ${ }^{1}$ Clinical trial data have demonstrated that anticoagulation therapy for prevention or treatment of VTE in patients with cancer, especially lowmolecular-weight heparins (LMWHs), prevents morbidity and may decrease mortality. ${ }^{3}$ However, despite evidence demonstrating the efficacy of 
anticoagulant therapy, VTE often goes unrecognized and may be treated suboptimally. Pharmacists are well positioned to aid in enhancing the management of cancer patients who have or are at risk of VTE.

The purpose of this review is to provide an overview of the epidemiology of thrombosis in patients with cancer, to highlight evidence pertaining to its treatment and prevention in this population and to suggest how pharmacists may play a role in improving the care of patients with cancer and VTE.

\section{Methods}

A literature review was conducted by searching MEDLINE, EMBASE and International Pharmacy Abstracts for articles published from January 1995 to August 2010 that examined clinical outcomes related to thrombosis and cancer and the pharmacist's role. Online formularies for Canadian provinces were also reviewed to determine coverage for LMWH used for this indication.

\section{Results}

\section{$D V T$ and $P E$}

Patients with cancer have a significantly greater risk of morbidity and mortality from thromboembolism relative to patients without cancer. Overall, $15 \%$ of patients with cancer will experience symptomatic DVT at some point, but this rate underestimates the importance of the problem when one considers that fully $50 \%$ of cancer patients experience asymptomatic DVT and that post-mortem studies have shown a DVT risk of $50 \%$ at autopsy, making VTE a possible cause of death in these cases. ${ }^{4}$ In fact, 1 in 7 cancer patients undergoing treatment in hospital dies because of pulmonary embolism. ${ }^{5}$ Among patients with cancer, the risk of death within 6 months of a VTE event is $94 \%, 3$ times the risk in patients without cancer. ${ }^{6}$ Although most VTE events are not fatal, they cause significant morbidity through postthrombotic syndrome, pain, possible drug interactions and increased readmission to hospital. ${ }^{2}$

\section{Risk of thrombosis}

Many factors that increase the risk of VTE are inherent to the patient, including thrombophilia, history of thromboembolic disease, advanced age, obesity and female sex. Other risk factors are related to cancer treatment, including oral contraceptives, hormone replacement therapy, tamoxifen therapy, central venous catheterization, chemotherapy (especially thalidomide and bevacizumab), radiotherapy, erythropoietin-stimulating agents, surgery, immobilization and admission to hospital. The cancer itself can influence the risk of thromboembolic disease and the incidence is higher (relative risk 1.02 to 4.34 ) among those with advanced disease and those with certain tumour types (specifically cancer of the pancreas or brain and lymphoproliferative disease). ${ }^{7}$ The presence of disseminated intravascular coagulation is also a known risk factor. Development of Virchow's triad, consisting of venous stasis secondary to compression by the tumour, secretion of prothrombotic factors and proinflammatory cytokines by the tumour and the endothelium and cancer-related damage to the endothelium, leads to the thromboembolic event. ${ }^{8}$

\section{Prophylaxis}

The frequency of VTE in cancer patients being treated in hospital ranges from $0.6 \%$ to $5.4 \% .^{9}$ Among medical inpatients with cancer, rates of VTE are lower with prophylaxis using LMWH, rather than unfractionated heparin (UFH) or placebo, without significantly higher rates of major bleeding. ${ }^{10}$ Three large randomized controlled trials demonstrated the efficacy of enoxaparin, dalteparin and fondaparinux, respectively, in preventing VTE in medical patients being treated in hospital (Table 1). ${ }^{11-13}$ In each of these trials, data were reported for nonrandomized cancer sub-

TABLE 1 Clinical trial data for prophylaxis of venous thromboembolism in acutely ill medical inpatients (cancer subgroup)

\begin{tabular}{l|c|c|c|c|c}
\hline \multirow{2}{*}{ Study and drug } & \multirow{2}{*}{$\begin{array}{c}\text { No. of } \\
\text { patients }\end{array}$} & \multirow{2}{*}{$\begin{array}{c}\text { No. (\%) } \\
\text { with cancer }\end{array}$} & \multicolumn{2}{|c|}{ No. (\%) of events } & \multirow{2}{*}{ RR (95\% CI) } \\
\cline { 4 - 6 } & 579 & $118(12.4)$ & $8 / 41(19.5)$ & $3 / 31(9.7)$ & $0.50(0.14-1.72)$ \\
\hline MEDENOX study ${ }^{11}$ (enoxaparin) & 3706 & $190(5.1)$ & $73 / 1473(5.0)$ & $42 / 1518(2.8)$ & $0.55(0.38-0.80)$ \\
\hline PREVENT study ${ }^{12}$ (dalteparin) & 849 & $131(15.4)$ & $34 / 323(10.5)$ & $18 / 321(5.6)$ & $0.47(0.08-0.69)$ \\
\hline ARTEMIS study ${ }^{13}$ (fondaparinux) & &
\end{tabular}

$\mathrm{RR}=$ relative risk $\mathrm{CI}=$ confidence interval. 


\section{Points clés}

- La thromboembolie veineuse est fréquente chez les patients atteints de cancer et se traduit par un taux élevé de morbidité et de mortalité.

- Divers anticoagulants peuvent être utilisés pour prévenir la thromboembolie veineuse chez les patients hospitalisés atteints de cancer.

- L'administration d'héparines de faible poids moléculaire sur une longue période (trois à six mois) a donné de meilleurs résultats que les anticoagulants oraux chez les patients cancéreux atteints d'une thromboembolie veineuse active. groups. Although these trials provided information about the efficacy of intervention, they had several limitations, including the limited number of cancer patients $(5 \%$ to $15 \%$ of the patients in each trial) and the fact that bleeding events were not reported for the cancer subgroups.

Patients with cancer who undergo surgery are at high risk of VTE. Without prophylaxis, rates of proximal vein thrombosis of $10 \%$ to $20 \%$ and rates of $\mathrm{PE}$ of $4 \%$ to $10 \%$ have been reported in surgical populations. ${ }^{14}$ The rate of $\mathrm{PE}$ after abdominal surgery in cancer patients is 14 times higher than among patients without cancer. ${ }^{15}$ The data clearly demonstrate the efficacy and safety of LMWH for prophylaxis of VTE in this population and the risk of VTE events declines by about $50 \%$ with prophylaxis. ${ }^{16}$

\section{Prophylaxis in ambulatory patients}

Preliminary data from randomized controlled trials involving ambulatory patients with cancer are conflicting. This, in combination with the known risk of bleeding in patients with cancer, suggests that prophylaxis is likely not warranted in the majority of ambulatory cancer patients given the benefit to risk ratio. Conversely, throm- boprophylaxis with a fixed, low dose of warfarin (1-2 mg/day) or a LMWH may be warranted for patients with multiple myeloma who are receiving thalidomide- or lenalidomide-based combination therapy. ${ }^{17}$ Further data are required for this population.

\section{Treatment of VTE}

Use of anticoagulants to treat VTE in cancer patients is associated with both substantial benefits and high rates of complications. Most cancer patients with VTE require anticoagulation, but anticoagulation may be withheld for a small subset of patients if there is no therapeutic advantage (e.g., for patients with a high risk of complications of VTE treatment, those whose expected survival is short, those with no planned oncological intervention and those for whom no palliative benefit is anticipated).

Several trials have assessed treatment of VTE with LMWH in patients with cancer (summarized in Table 2). The largest of these, the CLOT trial, compared dalteparin with vitamin $\mathrm{K}$ antagonists. ${ }^{18}$ Dalteparin was associated with a $52 \%$ relative risk reduction (RRR) in the incidence of recurrent VTE during the 6 months of follow-up. There were no significant differences between the 2 treatment groups in the rates of major bleeding or any bleeding. The CANTHANOX study, which was stopped early because of low recruitment, demonstrated a reduction in the primary end point (defined as either recurrent VTE or major bleeding or both) with enoxaparin therapy (7 vs 15 patients, $p=0.09) .{ }^{19}$ The end point was driven

TABLE 2 Randomized trials comparing low-molecular-weight heparin and warfarin in patients with cancer

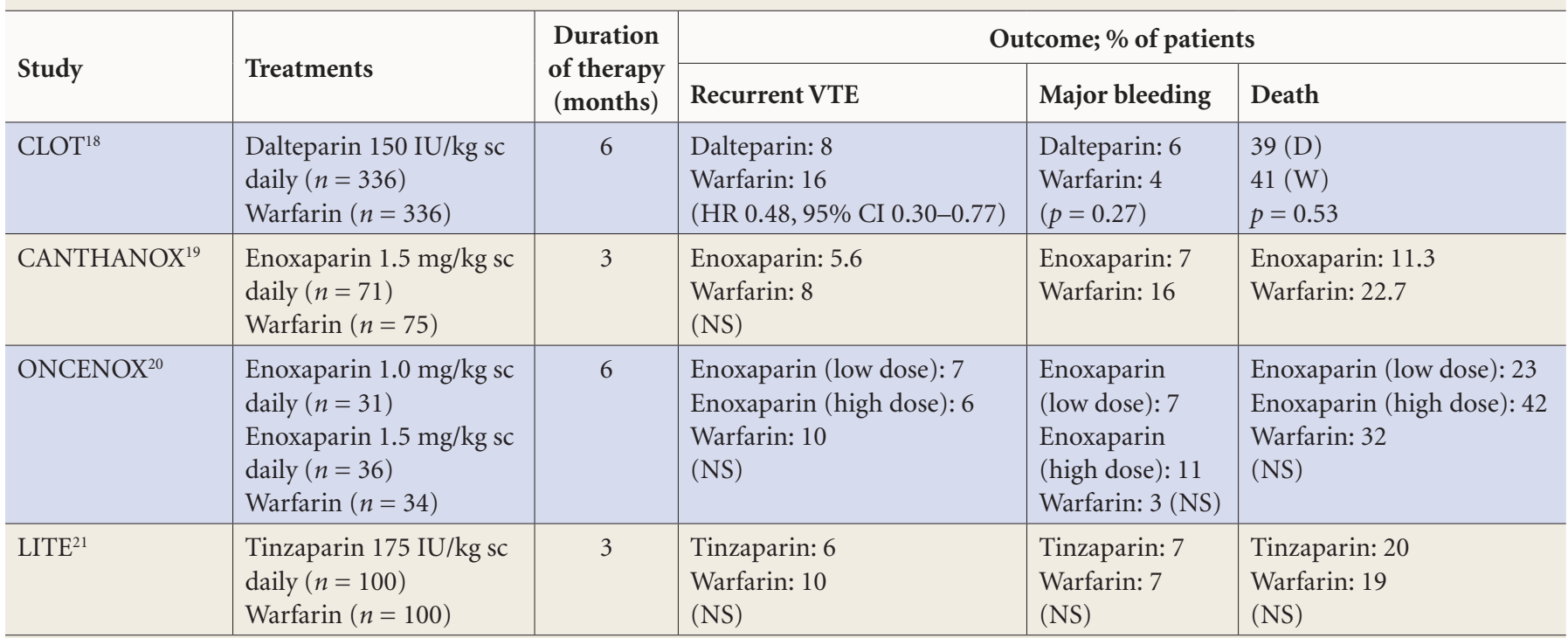

$\mathrm{VTE}=$ venous thromboembolism; $\mathrm{HR}=$ hazard ratio; $\mathrm{CI}=$ confidence interval; $\mathrm{NS}=$ not significant. 
by major bleeding (which occurred in 5 patients in the enoxaparin arm and 12 in the warfarin arm). The 3-armed ONCENOX study demonstrated no differences between the enoxaparin and warfarin groups in terms of recurrent VTE, major bleeding or death; however, the small sample size precludes strong conclusions. ${ }^{20}$ Tinzaparin was more effective than warfarin for 200 patients with cancer in the LITE study. ${ }^{21}$ In that study, tinzaparin reduced the rate of recurrent VTE by about $50 \%$, but the difference was not statistically significant. There were no differences in bleeding rates.

\section{Guidelines}

Given the prevalence and impact of VTE in patients with cancer, as well as the wealth of data demonstrating the efficacy and safety of prophylaxis and treatment of VTE in this population, several groups, including the American Society of Clinical Oncology (ASCO), ${ }^{9}$ the American College of Chest Physicians, ${ }^{22}$ the European Society for Medical Oncology ${ }^{23}$ and the National Comprehensive Cancer Network, ${ }^{24}$ have published guidelines for clinicians on this topic (summarized in Table 3).

Although the guidelines support use of LMWH for VTE prophylaxis in cancer patients who are being treated in hospital, a number of contraindications exist. In particular, the ASCO guidelines ${ }^{9}$ cite the following as relative contraindications: active uncontrollable bleeding; active cerebrovascular hemorrhage; dissecting or cerebral aneurysm; bacterial endocarditis, bacterial pericarditis or active peptic or other gastrointestinal ulceration; severe, uncontrolled or malignant hypertension; severe head trauma; and placement of an epidural catheter.

\section{Discussion}

Despite the data pertaining to the efficacy and safety of prophylaxis and treatment of VTE in cancer patients and several guidelines suggesting appropriate strategies, data from cohort studies suggest that only about half of patients eligible for appropriate therapy receive it. ${ }^{4,17,23}$ In understanding this treatment gap, it is important to consider various contributing factors, including whether patients are able to adhere to or gain access to available prophylactic or treatment regimens.

Available data suggest that patients are able to adhere to the LMWH regimens and find them acceptable as treatment strategies. For example, adherence to daily enoxaparin therapy was $94 \%$ to $97 \%$ in the ONCENOX trial, which exceeded the $92.8 \%$ adherence for warfarin. ${ }^{20}$ Lee et al. reported that $78 \%$ of eligible patients in the CLOT study found long-term self-injection of dalteparin acceptable. $^{18}$

In terms of accessibility, the various public drug plans across Canada are divergent in terms of coverage of these agents (Table 4)..$^{25-31}$

Despite recent evidence demonstrating the efficacy and safety of LMWH in the treatment of VTE in patients with cancer, vitamin $\mathrm{K}$ antagonists and UFH continue to be used in some set-

\section{TABLE 3 Summary of antithrombotic guidelines for patients with cancer}

\begin{tabular}{|c|c|c|c|}
\hline Patient group & Guideline & Recommendation & Agent \\
\hline Hospital inpatients & $\begin{array}{l}\text { ACCP, }{ }^{22} \text { ASCO, }{ }^{9} \\
\mathrm{ESMO}^{23}{ }^{23} \mathrm{NCCN}^{24}\end{array}$ & $\begin{array}{l}\text { In the absence of bleeding or other } \\
\text { contraindications, hospital inpatients should be } \\
\text { considered candidates for VTE prophylaxis. }\end{array}$ & UFH, LMWH or FPX \\
\hline $\begin{array}{l}\text { Ambulatory patients receiving } \\
\text { chemotherapy }\end{array}$ & $\begin{array}{l}\text { ASCO },{ }^{9} \mathrm{ESMO},{ }^{23} \\
\mathrm{NCCN}^{24}\end{array}$ & $\begin{array}{l}\text { Prophylaxis not generally recommended except } \\
\text { for patients at very high risk (those receiving } \\
\text { thalidomide or lenalidomide with chemotherapy). }\end{array}$ & $\begin{array}{l}\text { LMWH or adjusted-dose } \\
\text { warfarin }\end{array}$ \\
\hline $\begin{array}{l}\text { Patients scheduled to undergo } \\
\text { surgery }\end{array}$ & $\begin{array}{l}\text { ACCP, }{ }^{22} \text { ASCO, }{ }^{9} \\
\mathrm{ESMO}^{23}{ }^{23} \mathrm{NCCN}^{24}\end{array}$ & $\begin{array}{l}\text { Patients undergoing major surgical intervention } \\
\text { should be considered candidates for perioperative } \\
\text { prophylaxis. }\end{array}$ & $\begin{array}{l}\text { Low-dose UFH, LMWH or } \\
\text { FPX; consider longer-term } \\
\text { LMWH for some patients }\end{array}$ \\
\hline Patients with established VTE & $\begin{array}{l}\mathrm{ACCP}^{22} \mathrm{ASCO}^{9} \\
\mathrm{NCCN}^{24}\end{array}$ & $\begin{array}{l}\text { For patients with proximal DVT or pulmonary } \\
\text { embolism, extended prophylaxis with LMWH } \\
\text { (preferred over warfarin) is recommended. }\end{array}$ & LMWH \\
\hline
\end{tabular}

ACCP = American College of Clinical Pharmacy; ASCO = American Society of Clinical Oncology; ESMO = European Society for Medical Oncology; NCCN = National Comprehensive Cancer Network; VTE = venous thromboembolism; UFH = unfractionated heparin;

LMWH = low-molecular-weight heparin; FPX = fondaparinux; DVT = deep vein thrombosis. 
TABLE 4 Provincial coverage for low-molecular-weight heparin therapy

\begin{tabular}{|c|c|c|}
\hline Province $^{*}$ & Indications for LMWH & Difference in coverage between LMWH products \\
\hline $\begin{array}{l}\text { British } \\
\text { Columbia }^{25}\end{array}$ & $\begin{array}{l}\text { Associated with cancer, in patients who have either failed or } \\
\text { who are unable to tolerate oral therapy with warfarin up to } \\
6 \text { months. }\end{array}$ & None \\
\hline Saskatchewan ${ }^{26}$ & $\begin{array}{l}\text { - For treatment of VTE; up to } 10 \text { days. } \\
\text { - For long-term outpatient prophylaxis for patients with } \\
\text { contraindication to, intolerance to, or failure of warfarin } \\
\text { therapy. }\end{array}$ & None \\
\hline Manitoba $^{27}$ & $\begin{array}{l}\text { Specific criteria available from Exception Drug Status } \\
\text { Program, Manitoba Health. }\end{array}$ & None \\
\hline Ontario $^{28}$ & $\begin{array}{l}\text { Limited-use codes: } \\
\text { - 186: For treatment of acute DVT; maximum of } 3 \text { weeks. } \\
\text { 188: For DVT in patients for whom treatment with } \\
\text { warfarin is not tolerated or is contraindicated. } \\
\text { - 189: For DVT in patients in whom treatment with } \\
\text { warfarin has failed. } \\
\text { - 323: For treatment of acute PE; maximum of } 3 \text { weeks } \\
\text { (applicable only for enoxaparin and tinzaparin). }\end{array}$ & $\begin{array}{l}\text { - Criteria for Exceptional Access Program, applicable only } \\
\text { for dalteparin: For extended treatment of symptomatic } \\
\text { acute VTE in patients with cancer who cannot use } \\
\text { warfarin; approval duration as requested up to } 6 \\
\text { months. }\end{array}$ \\
\hline $\begin{array}{l}\text { Prince Edward } \\
\text { Island }^{29}\end{array}$ & $\begin{array}{l}\text { - For the acute treatment of deep vein thrombosis (DVT) } \\
\text { and/or pulmonary embolism (PE) for a maximum of } 10 \\
\text { days. } \\
\text { - For prophylaxis in hip replacement and hip fracture } \\
\text { surgery, approval is limited to a maximum of } 35 \text { days. } \\
\text { - For prophylaxis in knee replacement surgery, approval is } \\
\text { limited to a maximum of } 10 \text { days. } \\
\text { - For prophylaxis in high-risk surgery, approval is limited to } \\
\text { maximum of } 10 \text { days. }\end{array}$ & None \\
\hline $\begin{array}{l}\text { Newfoundland } \\
\text { and Labrador }{ }^{30}\end{array}$ & $\begin{array}{l}\text { - Treatment of acute VTE, to maximum of 7-10 days } \\
\text { (limited coverage). } \\
\text { - Extended treatment of recurrent VTE in patients with } \\
\text { treatment failure on therapeutic doses of warfarin. } \\
\text { - Prophylaxis in patients who have not reached therapeutic } \\
\text { INR while taking oral anticoagulant therapy. }\end{array}$ & $\begin{array}{l}\text { Same for } 3 \text { indications listed in preceding column. } \\
\text { Dalteparin has the following further indication: } \\
\text { Anticoagulation in patients with cancer: } \\
\text { For the treatment of VTE in cancer patients: } \\
\text { - Acute treatment limited to } 10 \text { days (while } \\
\text { warfarinizing) } \\
\text { - Extended treatment in symptomatic VTE in cancer } \\
\text { patients who have had a recurrent VTE on warfarin } \\
\text { therapy. Coverage will be limited to a } 3 \text { month period. } \\
\text { For the secondary prevention of symptomatic VTE: } \\
\text { - For cancer patients who are on active chemotherapy } \\
\text { with agents which interact with warfarin or in patients } \\
\text { who have failed oral anticoagulants as evidenced by an } \\
\text { extension or recurrence of DVT. } \\
\text { - Maximum treatment duration } 6 \text { months. } \\
\text { - Please note that the routine use of LMWH in cancer } \\
\text { patients to improve survival was reviewed and not } \\
\text { recommended as there was no consistent evidence to } \\
\text { support use. }\end{array}$ \\
\hline New Brunswick ${ }^{31}$ & $\begin{array}{l}\text { - Open listing: Automatic reimbursement for one } \\
\text { prescription claim annually for treatment of DVT and/or } \\
\text { PE, to maximum of } 10 \text { days. } \\
\text { - Special authorization required for extended treatment of } \\
\text { recurrent symptomatic VTE occurring while patient is } \\
\text { receiving therapeutic dose of warfarin. }\end{array}$ & None \\
\hline
\end{tabular}

LMWH = low-molecular-weight heparin; DVT = deep vein thrombosis; PE = pulmonary embolism; INR = international normalized ratio; $\mathrm{VTE}=$ venous thromboembolism.

${ }^{\star}$ For Alberta, Quebec and Nova Scotia, as well as First Nations and Inuit (under the Non-Insured Health Benefits program), there is an open listing for indications for LMWH and no differences in coverage between different LMWH products. 
tings. ${ }^{5}$ Although the acquisition cost of vitamin $\mathrm{K}$ antagonists may be lower than those of LMWHs, these agents may be less effective and more challenging to use in this population. Even in patients who do not have cancer, warfarin control is often suboptimal in the community setting and the time within the therapeutic range is well under $50 \% .^{32}$ If warfarin dosing is managed traditionally, maintenance of the dose within a therapeutic range, as indicated by time within target INR range, is likely worse for cancer patients than for noncancer patients and is challenging even if dosing is managed by an anticoagulation clinic. Suboptimal INR control may result from multiple drug and food interactions, which may be more likely in cancer patients who are receiving chemotherapy and antiemetic therapy. Liver dysfunction, borderline vitamin $\mathrm{K}$ deficiency and gastrointestinal disorders such as vomiting and diarrhea, which are common among cancer patients, may affect the response to vitamin $\mathrm{K}$ antagonists. Furthermore, maintaining therapeutic warfarin control may necessitate weekly INR monitoring, which can be inconvenient for patients.

Pharmacists should ensure that the therapeutic approach to anticoagulant therapy for cancer patients is evidence-based and consistent with the literature, published guidelines and patient preferences. As well, pharmacists should be vigilant in reviewing the patient's medication profile for agents such as hormone replacement therapy, oral contraceptives, tamoxifen, thalidomide, bevacizumab and erythropoietin-stimulating agents to ensure that consideration is given to prevention and treatment of thrombosis risk that may be increased by these agents. The authors of the Oncology Workforce Study in the United States recommended that oncology pharmacists can play an important role in preventing and managing thrombosis. ${ }^{33}$ Given the impact that pharmacists have had in a wide variety of other disease states, it is only logical that they work to ensure optimal care of cancer patients who have experienced or are at risk of experiencing VTE. Through discussions with patients, pharmacists can better understand the options that have been offered and the choices that have already been made. For example, if the patient has active VTE and is being treated with warfarin, the pharmacist can determine if LMWH has been offered and, if not, can collaborate with the patient and the physician to determine if this might be a preferable treatment strategy, given currently available evidence and the limitations and challenges associated with warfarin anticoagulation. If warfarin is the preferred strategy, the pharmacist should work with the patient and the physician to optimize warfarin control. Bungard et al. recently published a practice tool and practical management tips that pharmacists may find helpful in ensuring best outcomes with warfarin therapy. ${ }^{34}$ The Anticoagulation Forum has suggested that patients who are taking warfarin must receive information about the common signs and symptoms of thrombosis and bleeding and what to do if they occur. The common signs of thrombosis include shortness of breath and painful, swollen calves. Bleeding events that are commonly associated with anticoagulant therapy include bruising, minor bleeding, nosebleeds and more significant bleeding events, which may manifest as black stools, blood in the stool, rectal bleeding and vomiting of material with the appearance of coffee grounds. Patients should be advised that if any of these events occur (other than bruising, minor nosebleeds and other types of minor bleeding), they should seek medical attention. ${ }^{35}$

Regardless of the selected antithrombotic therapy, pharmacists are in a position to educate patients about the risk of VTE, the risk of bleeding and directions for care if such an event occurs. They can also emphasize the importance of adherence with therapy. Pharmacists should also work with the patient and other caregivers to minimize the impact of drug interactions involving anticoagulant therapy.

\section{Conclusions}

Patients with cancer are at high risk of VTE, which can result in significant morbidity and mortality. Recent evidence has demonstrated the value of anticoagulant therapy and the use of LMWHs in these patients. All provincial drug plans in Canada have recognized the value of this therapeutic approach and have made these agents available either on an open-listing basis or with specific criteria. In addition, utilization of these agents is acceptable to patients. Given the efficacy and safety data pertaining to LMWH and the challenges of using warfarin in patients with cancer, pharmacists are well positioned to advocate for the approach that best meets patients' needs and to ensure that the selected approach is implemented.
From the Regina

Qu'Appelle Health

Region (Semchuck),

Regina, Saskatchewan;

and the Hôpital

Charles-Lemoyne

(Sperlich), Greenfield

Park, Quebec.

Contact bill.semchuk@

rqhealth.ca. 


\section{References}

1. Blom JW, Vanderschoot JP, Oostindier MJ, et al. Incidence of venous thrombosis in a large cohort of 66,329 patients with cancer: results of a record linkage study. J Thromb Haemost 2006;4:529-35.

2. Khorana AA, Francis CW, Culakova E, et al. Thromboembolism is a leading cause of death in cancer patients receiving outpatient chemotherapy. J Thromb Haemost 2007;5:632-4.

3. Akl E, Rohilla S, Barba M, et al. Anticoagulation for the initial treatment of venous thromboembolism in patients with cancer: a systematic review. Cancer 2008;113(7):1685-94

4. Falanga A, Zacharski L. Deep vein thrombosis in cancer: the scale of the problem and approaches to management. Ann Oncol 2005;16:696-701.

5. Kakkar AK, Levine M, Pinedo HM, et al. Venous thrombosis in cancer patients: insights from the FRONTLINE survey. Oncologist 2003;8;381-8.

6. Sorensen HT, Mellemkjaer L, Olsen JH, et al. Prognosis of cancers associated with venous thromboembolism. N Engl J Med 2000;242:1846-50.

7. Stein PD, Beemath A, Meyers FA, et al. Incidence of venous thromboembolism in patients hospitalized with cancer. Am J Med 2006;119(1):60-8.

8. Sood SL. Cancer-associated thrombosis. Curr Opin Hematol 2009;16:378-85. 9. Lyman GH, Khorana AA, Falanga A, et al. American Society of Clinical Oncology guideline: recommendations for venous thromboembolism prophylaxis and treatment in patients with cancer. J Clin Oncol 2007;25:5490-505.

10. Kanaan AO, Silva MA, Donovan JL, et al. Meta-analysis of venous thromboembolism prophylaxis in medically ill patients. Clin Ther 2007;29:2395-405. 11. Samama MM, Cohen AT, Darmon JY, et al.; Prophylaxis in Medical Patients with Enoxaparin Study Group. A comparison of enoxaparin with placebo for the prevention of venous thromboembolism in acutely ill medical patients. $N$ Engl J Med 1999;341:793-800.

12. Leizorovicz A, Cohen AT, Turpie AG, et al.; PREVENT Medical Thromboprophylaxis Study Group. Randomized, placebo-controlled trial of dalteparin for the prevention of venous thromboembolism in acutely ill medical patients. Circulation 2004;110:874-9.

13. Cohen AT, Davidson BL, Gallus AS, et al. Efficacy and safety of fondaparinux for the prevention of venous thromboembolism in older acute medical patients; randomised placebo controlled trial. BMJ 2006;332:325-9.

14. Geerts WH, Bergqvist D, Pineo GF, et al. Prevention of venous thromboembolism: American College of Chest Physicians Evidence-Based Clinical Practice Guidelines (8th edition). Chest 2008;133(6 Suppl):381S-453S.

15. Petersen LJ. Anticoagulation therapy for prevention and treatment of venous thromboembolic events in cancer patients: a review of current guidelines. Cancer Treat Rev 2009:35:754-64.

16. Clagett GP, Reisch JS. Prevention of venous thromboembolism in general surgical patients. Results of meta-analysis. Ann Surg 1988;208(2):227-40.

17. Khorana AA. Cancer and thrombosis: implications of published guidelines for clinical practice. Ann Oncol 2009;20:1619-30.

18. Lee AY, Levine MN, Baker RI, et al. Low-molecular-weight heparin vs a coumarin for the prevention of recurrent venous thromboembolism in patients with cancer. $N$ Engl J Med 2003;349:146-53.

19. Meyer G, Marjanovic Z, Valcke J, et al. Comparison of low-molecularweight heparin and warfarin for the secondary prevention of venous thromboembolism in patients with cancer: a randomized controlled study. Arch Intern Med 2002;162:1729-35.

20. Deitcher SR, Kessler CM, Merli G, et al.; ONCENOX Investigators. Secondary prevention of venous thromboembolic events in patients with active cancer: enoxaparin alone versus initial enoxaparin followed by warfarin for a 180-day period. Clin Appl Thromb Hemost 2006;12:389-96.

21. Hull RD, Pineo GF, Brant RF, et al. Long-term low-molecular-weight heparin versus usual care in proximal vein thrombosis patient with cancer. Am J Med 2006;119:1062-72.

22. Kearon C, Kahn SR, Agnelli G, et al. Antithrombotic therapy for venous themboembolic disease: American College of Chest Physicians Evidence-based Clinical Practice Guidelines (8th edition). Chest 2008;133(6 Suppl):454S-545S. 23. Mandalà M, Falanga A, Roila F; ESMO Guidelines Working Group. Management of venous thromboembolism in cancer patients: ESMO clinical recommendations. Ann Oncol 2008;19 Suppl 2:ii126-7

24. Wagman LD, Baird MF, Bennett CL, et al.; National Comprehensive Cancer Network. Venous thromboembolic disease. Clinical practice guidelines in oncology. J Natl Compr Canc Netw 2006;4:838-69.

25. British Columbia Ministry of Health. Limited Coverage Drug. Special Authority Criteria. Available: https://www.health.gov.bc.ca/exforms/ pharmacare/5338fil.pdf (accessed Dec. 7, 2011).

26. Saskatchewan Ministry of Health. Online formulary. Exception Drug Status Program. Available: http://formulary.drugplan.health.gov.sk.ca/ default.htm?AppendixA.asp (accessed Dec. 7, 2011).

27. Government of Manitoba. Part 3: exception drug status (EDS). Available: www.gov.mb.ca/health/mdbif/edsnotice.pdf (accessed Dec. 7, 2011).

28. Ontario Drug Benefit Formulary/Comparative Drug Index, No. 41. Available: www.health.gov.on.ca/english/providers/program/drugs/formulary/edition_41.pdf (accessed Dec. 7, 2011).

29. Health PEI. PEI Pharmacare Formulary. Available: www.gov.pe.ca/photos/ original/hpei_formulary.pdf (accessed Dec. 7, 2011).

30. Newfoundland and Labrador Interchangeable Drug Products Formulary. Available: www.health.gov.nl.ca/health/nlpdp/fmlsearch.asp (accessed Dec. 7, 2011).

31. New Brunswick Prescription Drug Program. Special authorization criteria. September 2011.Available: www.gnb.ca/0212/pdf/special_auth/Special_Authorization_Criteria-e.pdf (accessed Dec. 7, 2011).

32. Bungard TJ, Ackman ML, Ho G, Tsuyuki RT. Adequacy of anticoagulation in patients with atrial fibrillation coming to a hospital. Pharmacotherapy 2000;20:1060-5.

33. Sessions JK, Valgus J, Barbour SY, Iacovelli L. Role of oncology clinical pharmacists in the light of the Oncology Workforce Study. J Oncol Pract 2010;6:270-2.

34. Bungard TJ, Yakiwchuk E, Foisy M, et al. Drug interactions involving warfarin: practice tool and practical management tips. Can Pharm J 2011;144(1):21-5.

35. Garcia DA, Witt DM, Hylek E, et al. Delivery of optimized anticoagulant therapy: consensus statement from the Anticoagulation Forum. Ann Pharmacother 2008;42:979-88. 